\title{
Alumina/water suspensions in the presence of PEO-PPO-PEO triblock copolymers
}

\author{
Aylin Şakar-Deliormanlı, ${ }^{\mathrm{a},}$, Hürriyet Polat ${ }^{\mathrm{b}}$, Muhsin Çiftçioğlu ${ }^{\mathrm{a}}$ \\ ${ }^{a}$ Chemical Engineering Department, Izmir Institute of Technology, Gülbahce Köyü, 35430 Urla, İzmir Turkey \\ ${ }^{\mathrm{b}}$ Chemistry Department, Izmir Institute of Technology, Faculty of Science, Gülbahce Köyü, 35430 Urla, İzmir Turkey
}

Received 10 May 2003; received in revised form 23 September 2003; accepted 4 October 2003

\begin{abstract}
The aim of this study was to investigate the stability and dispersion behaviour of aqueous alumina suspensions in the presence of polyethylene oxide-polypropylene oxide-polyethylene oxide (PEO-PPO-PEO) type triblock copolymers. For this purpose alumina suspensions at various solids loadings were prepared using four different methods. These are: Method I: powder and water were stirred only; Method II: powder and water were stirred and ultrasonic treatment was applied; Method III: powder and water were stirred in the presence of block copolymers; Method IV: powder and water were stirred and ultrasonic treatment was applied in the presence of block copolymers. These suspensions were characterized by means of rheological measurements. Sedimentation and turbidity measurements were also conducted to support these results and to investigate the stability of these systems for longer times. Surface tension measurements were performed to investigate the adsorption behaviour of block copolymers onto alumina surface. It was found that the use of PEO-PPO-PEO type triblock copolymers improved the dispersion behaviour of aqueous alumina suspensions in the presence of ultrasonic treatment at low solids loadings. However their effect was not significant at high solids loadings and without ultrasonic treatment.
\end{abstract}

(C) 2003 Elsevier Ltd. All rights reserved.

Keywords: $\mathrm{Al}_{2} \mathrm{O}_{3}$; Block copolymers; Stability; Suspensions

\section{Introduction}

The interaction of dispersed particles in aqueous systems with each other and with the surrounding phase has a great importance for ceramic processing. The preparation of high quality ceramics necessitates the successful dispersion of powders and the preparation of stable suspensions. Alumina $\left(\mathrm{Al}_{2} \mathrm{O}_{3}\right)$ is the most widely used oxide ceramic because it is plentiful, relatively low in cost and equal to or better than most oxides in mechanical properties. ${ }^{1}$ Alumina powders in aqueous media are normally very unstable because of the tendency of fine powder particles to agglomerate. Consolidation of these powders may usually involve the use of stable suspensions.

When $20 \mathrm{kHz}$ ultrasound is applied to water, a great deal of mechanical agitation is produced; hence this

\footnotetext{
* Corresponding author. Tel.: +90-232-4986246; fax: +90-2324986355 .

E-mail address: aylindeliormanli@iyte.edu.tr (A. ŞakarDeliormanl1).
}

method is commonly used in the dispersion of colloidal material in aqueous solutions. On the other hand, organic additives play a significant role in stabilization because they offer an effective means of modifying particle-particle interactions. Therefore, the mechanism of polymer adsorption and its effect on the stability of dispersions are important in controlling the properties of the ceramic suspensions. When adsorbed on inorganic surfaces, these species impart electrostatic, steric or electrosteric stabilization. ${ }^{2,3}$ In the non-adsorbed state, they can induce depletion stabilization depending on their concentration in solution, their charge and relative size ratio between the solid particles and additives. Depletion stabilization refers to stabilization of colloidal suspensions by polymers in free solution. ${ }^{4}$ In the case of the approach of two particles from a large separation distance, closer approach of the particles must be accompanied by demixing of the polymer molecules and the solvent in the interparticle region. Consequently, work must be done to make the polymer molecules leave the interparticle region. This corresponds 


\begin{tabular}{|c|c|}
\hline \multicolumn{2}{|c|}{ Nomenclature } \\
\hline$\Psi$ & Surface potential of material (volts) \\
\hline$\varepsilon$ & Relative permittivity of water (78.5) \\
\hline$\varepsilon_{\mathrm{o}}$ & $\begin{array}{l}\text { Permitivity of vacuum }\left(8.85 \times 10^{-12} \mathrm{C}^{2} / \mathrm{J}\right. \\
\mathrm{m})\end{array}$ \\
\hline $\mathrm{k}$ & Boltzman constant $\left(1.380658 \times 10^{-23} \mathrm{~J} / \mathrm{K}\right)$ \\
\hline $\mathrm{a}$ & Particle radius \\
\hline$\kappa$ & $\begin{array}{l}\text { Inverse thickness of the electrical double } \\
\text { layer }\left(\mathrm{m}^{-1}\right)\end{array}$ \\
\hline $\mathrm{h}$ & Separation distance between the particles \\
\hline $\mathrm{T}$ & Absolute temperature $(\mathrm{K})$ \\
\hline $\mathrm{A}_{121}$ & Hamaker constant of the particle in liquid \\
\hline $\mathrm{Vt}$ & $\begin{array}{l}\text { Total energy of interaction between the } \\
\text { particles }\end{array}$ \\
\hline Va & $\begin{array}{l}\text { Attractive energy of interaction between } \\
\text { the particles }\end{array}$ \\
\hline $\mathrm{Vr}$ & $\begin{array}{l}\text { Repulsive energy of interaction between } \\
\text { the particles }\end{array}$ \\
\hline $\mathrm{F}$ & Faraday constant ( $96484.6 \mathrm{coul} / \mathrm{mol})$ \\
\hline $\mathrm{z}$ & Valence of the counter ion \\
\hline $\mathrm{C}_{\mathrm{o}}$ & Electrolyte concentration of the solution \\
\hline $\mathrm{R}$ & Gas constant $(8.3144 \mathrm{~J} / \mathrm{mol} \mathrm{K})$ \\
\hline
\end{tabular}

to repulsion between the particles that, if high enough, can lead to stabilization of the suspension.

Many scientists investigated the effect of different type of dispersants such as polyacrylic acid, polymethacrylic acid, citric acid, sodium dodecyl sulfate, benzoic acid derivatives, anionic and cationic surfactants on the dispersion and stabilization behaviour of alumina powders in aqueous media. ${ }^{5-11}$

Polyethylene oxide-polypropylene oxide-polyethylene oxide (PEO-PPO-PEO) type block copolymers are non-ionic macromolecular surface active agents. They are effective over a wide $\mathrm{pH}$ range, wide structural variations make them effective for a variety of particle types and their high molecular weight provides effective steric stabilization. ${ }^{12}$ There are many studies related with dispersion and adsorption behaviour of these polymers on various materials. ${ }^{13-18}$ However there is no attention on the use of these polymers with alumina powders. The aim of the present work was to investigate the effects of PEO-PPO-PEO type block copolymers on the stability of alumina/water suspensions.

\section{Experimental}

\subsection{Materials}

A commercial high purity $\alpha-\mathrm{Al}_{2} \mathrm{O}_{3}$ powder, AKP-53, from Sumitomo Chemicals with an average particle size of $0.29 \mu \mathrm{m}$, a BET surface area of $12.3 \mathrm{~m}^{2} / \mathrm{g}$, tapped bulk density of $1.5 \mathrm{~g} / \mathrm{cm}^{3}$ and loose bulk density of $1.1 \mathrm{~g} / \mathrm{cm}^{3}$ was used in this study. The powder purity exceeded $99.99 \%$, containing $140 \mathrm{ppm} \mathrm{Si}, 7 \mathrm{ppm} \mathrm{Na}$, $20 \mathrm{ppm} \mathrm{Mg},<1 \mathrm{ppm} \mathrm{Cu}$ and 9 ppm Fe. Fig. 1 shows the SEM picture of AKP-53 powder.

PEO-PPO type triblock copolymers were obtained from BASF Corporation, Washington, NJ. They are non-ionic, water soluble surface active agents. These triblock copolymers posses symmetrical structure $(\mathrm{EO})_{x}(\mathrm{PO})_{y}(\mathrm{EO})_{x}$ where $x$ and $y$ denote the number of ethylene oxide and propylene oxide units. Important properties and general structure of triblock copolymers are given in Table 1 and Fig. 2, respectively.

Polyacrylic acid with an average molecular weight of $2000 \mathrm{~g} / \mathrm{mol}$ was obtained from Aldrich Chemicals. Distilled water used in the experiments was produced by Jencons Autostills DDI/C and had a conductivity of $113.5 \mu \mathrm{S} / \mathrm{cm}\left(24.6^{\circ} \mathrm{C}\right)$.

\subsection{Suspension preparation methods}

Suspensions were prepared at various solids loadings namely $0.125,1,10,20 \mathrm{vol} . \%$, using different methods

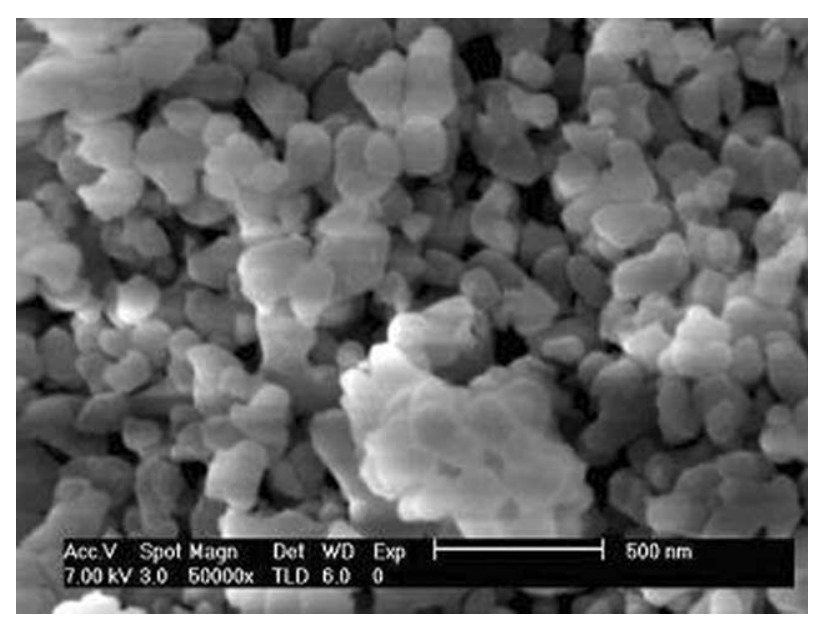

Fig. 1. SEM micrograph of AKP-53 alumina powder.

Table 1

Important properties of surfactants used in this study

\begin{tabular}{llllll}
\hline Code & $\mathrm{Mw}$ & Composition & PEO $\%$ & Melting point $\left({ }^{\circ} \mathrm{C}\right)$ & Viscosity $(\mathrm{cps})$ \\
\hline F-127 & 12600 & $\mathrm{EO}_{97} \mathrm{PO}_{69} \mathrm{EO}_{97}$ & 70 & 56 & 3100 \\
F-68 & 8400 & $\mathrm{EO}_{78} \mathrm{PO}_{30} \mathrm{EO}_{78}$ & 80 & 52 & 1000 \\
PAA & $2000(\mathrm{GPC})$ & Poly (acrylic acid $)$ & & & $70(\mathrm{C}=50 \%)$ \\
\hline
\end{tabular}




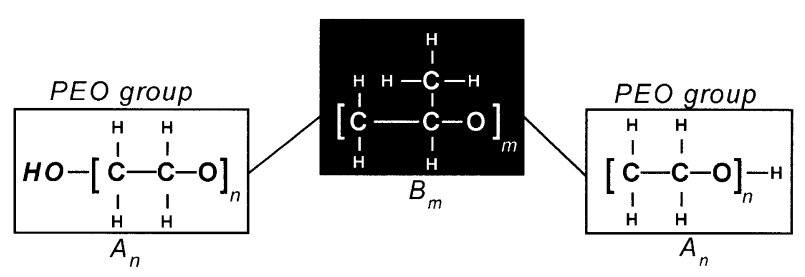

Fig. 2. Structure of PEO-PPO-PEO triblock copolymers.

Table 2

Suspension preparation methods

\begin{tabular}{lcccc}
\hline & Method I & Method II & Method III & Method IV \\
\hline Stirring & $\bullet$ & $\bullet$ & $\bullet$ & $\bullet$ \\
Ultrasonic treatment & & $\bullet$ & & $\bullet$ \\
Use of surfactants & & & $\bullet$ & $\bullet$ \\
\hline
\end{tabular}

(Table 2). During the experiments no $\mathrm{pH}$ adjustment were applied to the samples and the $\mathrm{pH}$ of the suspensions containing block copolymer was measured to be in the range of 5.7 and 6.8 .

\subsection{Characterization}

Rheological behaviour of the suspensions was determined by using Brookfield DV-III RV rheometer with an UL adaptor. Viscosities and shear stresses of the suspensions were measured at different shear rates under the following input conditions:

- initial shear rate was set at a shear $50 \mathrm{~s}^{-1}$;

- it was increased to $250 \mathrm{~s}^{-1}$ by $10 \mathrm{~s}^{-1}$ in every 30 s.; and

- it was again decreased down to $50 \mathrm{~s}^{-1}$ by $10 \mathrm{~s}^{-1}$ in every $30 \mathrm{~s}$.

Stability of suspensions with varying solids loadings (from 20 to 0.125 vol. \%) was tested by sedimentation studies. Once the suspension was prepared, stirring was stopped and it was poured into a test tube and the particles were allowed to settle under hindered settling conditions. The height of the sediment, which occurred between the settled particles and the clear liquid part of the suspension, was measured as a function of time up to 3 months. Stability of dilute suspensions $(0.125$ vol.\%) was studied using turbidity measurements in a Hach model 2100AN turbidimeter. The measurements were performed in time scales of $15 \mathrm{~s}$ to $64 \mathrm{~min}$.

The zeta potentials of particles in suspensions were determined using Zeta-Sizer 3000HSD from Malvern. The data obtained from these measurements were used to calculate the total interaction potential of the systems.

Surface tension measurements were utilized to study the adsorption behaviour of the surfactants onto alumina surface. Mixtures of PEO-PPO-PEO block copo- lymer/water with alumina and without alumina were prepared by Method IV and left for equilibrium at $25^{\circ} \mathrm{C}$. Suspensions of alumina and block copolymers were stirred for $10 \mathrm{~min}$ to $72 \mathrm{~h}$ to observe the adsorption kinetics. Then they were centrifuged at a high speed (6000 rpm) to separate the powder and the liquid phase. The surface tensions of the supernatants resulting from the separation of the alumina particles were measured by a Kruss-Digital Tensiometer K 10ST employing Wilhelmy plate method. The measurements were performed at $25^{\circ} \mathrm{C}$ and the platinum plate was heated in a flame until it glowed red before each measurement. The surface tension of each sample was measured for three times.

\section{Results and discussion}

\subsection{Rheological measurements}

Alumina suspensions prepared by four different methods were characterized by means of rheological measurements at four different solids loadings of 20, 10 , 1 and 0.125 vol.\%. These results are presented and discussed in the following paragraphs.

\subsubsection{Effect of suspension preparation methods}

Results are plotted as viscosity versus shear rate graphs in terms of increasing and decreasing rate sweeps. Fig. 3a gives the effect of Method I (stirring only) on the rheological behaviour of alumina suspension at $20 \mathrm{vol} . \%$. It can be seen that there is a big difference between the initial increasing and later decreasing rate sweeps. This is most probably due to the presence of flocculates since only stirring was applied to disperse the particles. Initial part of the curve has typical shear thinning character with $1.34 \mathrm{~N} / \mathrm{m}^{2}$ yield stress. Fig. $3 \mathrm{~b}$ gives the results of Method II where the suspension was subjected to the ultrasonic treatment besides stirring. The use of ultrasonic treatment improved the rheological behaviour of the suspension. The suspension showed Newtonian behaviour. There was not any difference between the increasing and the decreasing rate sweeps in this case. This is the indication of a well dispersed suspension. Fig. 3c shows the effect of Method III where the suspension was stirred in the presence of a block copolymer, F-127 at a concentration of $10^{-3} \mathrm{M}$ without ultrasonic treatment. In this case the suspension properties showed a shear thinning behaviour and the system was not well dispersed. Fig. 3d shows the effect of Method $\mathrm{IV}$, which gives the combined effect of ultrasonic treatment and F-127 at a concentration of $10^{-3} \mathrm{M}$. It can be seen from the figure that the suspension is well dispersed and there is no significant difference between the suspensions prepared by methods II and IV. 


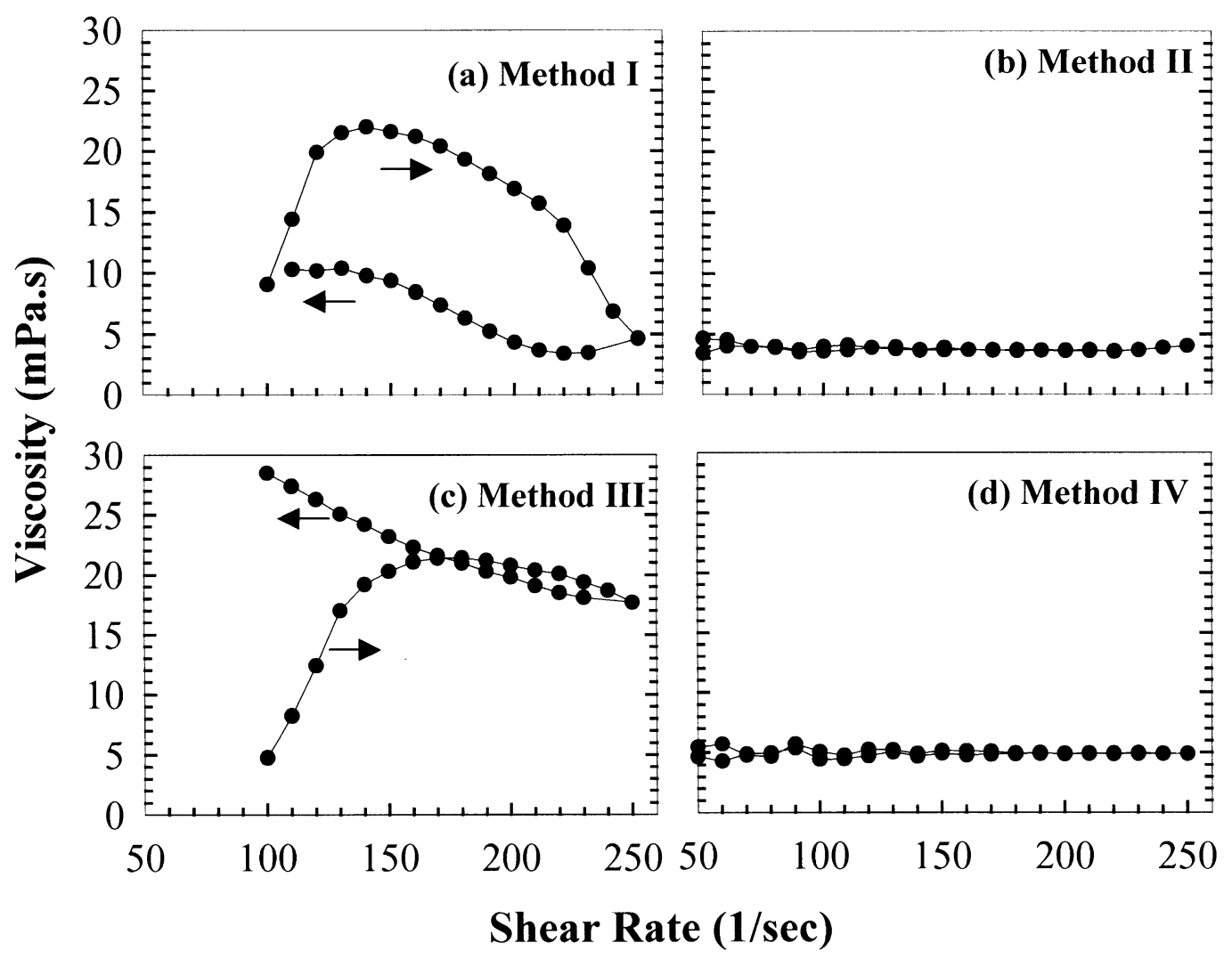

Fig. 3. Effect of suspension preparation method on the rheological behaviour of aqueous alumina suspensions. Solids loading: 20 vol.\%; Powder: AKP-53, surfactant concentration: $10^{-3}$ M F-127 for (c) and (d).

\subsubsection{Effect of solids loading}

Similar types of studies were also repeated for other solids loadings as 10,1 and 0.125 vol.\%. The rheological measurement results of the suspensions at $10 \mathrm{vol} . \%$ was nearly identical to the suspensions at 20 vol. $\%$. On the other hand suspensions with lower solids loadings did not show any flocculation at all for all the methods tested, since particle concentration was too low for these systems. Therefore, these results are not presented here.

\subsubsection{Effect of surfactant type and concentration}

Effect of dispersant concentration $\left(10^{-6}, 10^{-4}, 10^{-3}\right.$ M) and type (F-127, F-68) were tested by using Method IV. Polyacrylic acid (PAA) was also used for comparison purposes since it is a well known dispersant for aqueous alumina systems. The results of these studies were given in Fig. 4 in terms of shear stress versus shear rate plots. It is seen that the system is well dispersed in all cases except the highest concentration $\left(10^{-3} \mathrm{M}\right)$ of PAA. At this concentration system was flocculated and no data could be recorded. This shows that use of block copolymers in the presence of ultrasonic treatment are not harmful to the alumina/water system at any concentration but PAA seems to bring flocculation at higher concentrations $\left(10^{-3} \mathrm{M}\right)$ because of the increase in ionic strength. For concentrations $\left(10^{-6}, 10^{-4} \mathrm{M}\right)$, however, the effect was similar to that obtained with F-
127 and F-68. The $\mathrm{pH}$ of the suspensions containing 20 vol. $\%$ alumina and PAA at $10^{-6}, 10^{-4}$ and $10^{-3} \mathrm{M}$ concentrations were measured as $7.2,5.3$ and 3.4 , respectively.

It is well established that fraction of dissociated functional groups for a PAA chain varies with solvent conditions. Potentiometric titrations have shown that PAA is entirely negative at $\mathrm{pH}$ values above 6 whereas near and below $\mathrm{pH} 4$ the fraction of the dissociated carboxylic acid groups is almost zero and the polyelectrolyte is neutral. ${ }^{3}$

Cesarano and Aksay ${ }^{19}$ investigated the behavior of PAA in aqueous alumina suspensions at different $\mathrm{pH}$ values. According to their study the carboxylic groups dissociate more with increasing $\mathrm{pH}$, resulting in chain straightening due to repulsion between the monomer units. As the $\mathrm{pH}$ is decreased, the number of negatively charged sites is continually decreased until the PAA chains approach insolubility and form relatively small coils. Therefore the $\mathrm{pH}$ of the medium and concentration strongly affects the dispersion behaviour of PAA in aqueous alumina systems.

The viscosity values of alumina/water suspensions in the presence of PEO-PPO-PEO are also presented in Figs. 5 and 6 to show the effects of the method type and the block copolymer concentration. The viscosity of the suspensions prepared by Method II and Method IV 


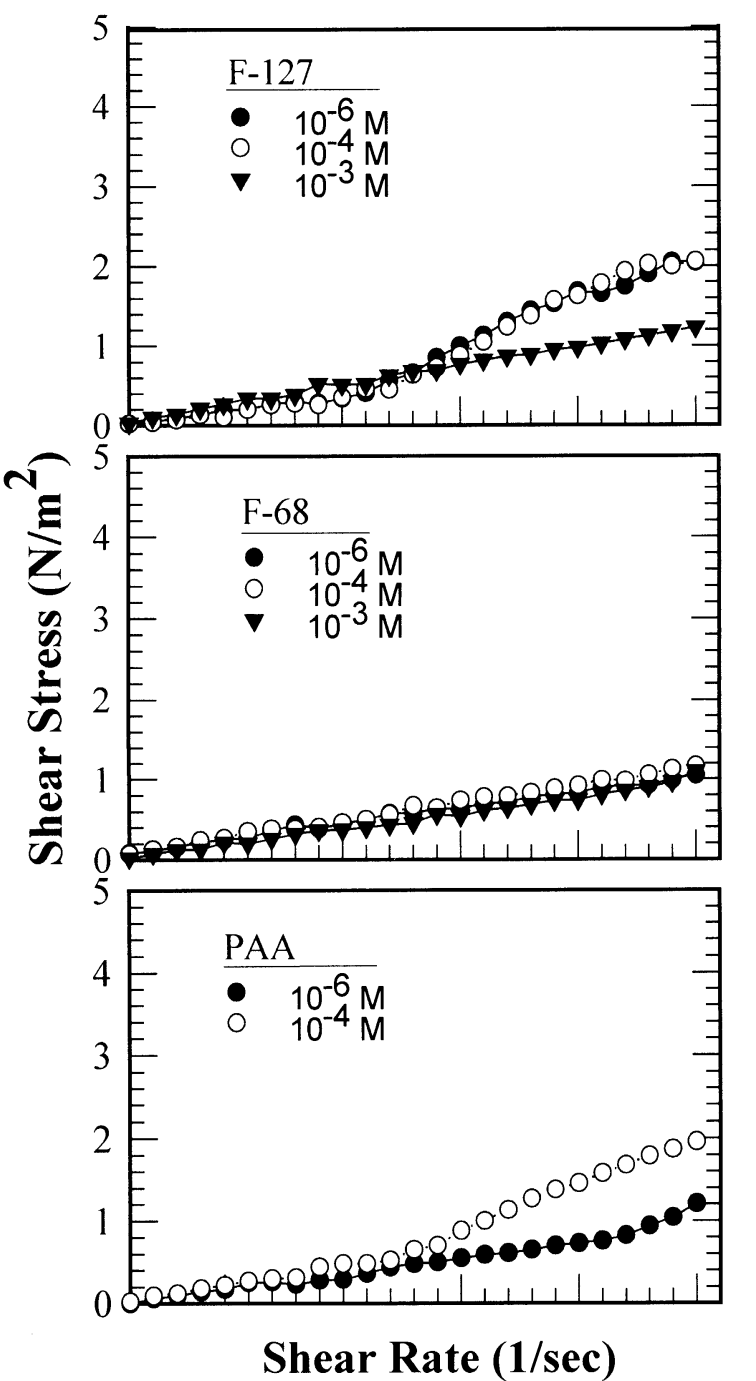

Fig. 4. Effect of block copolymers and polyacrylic acid on the rheological behaviour of aqueous alumina suspensions. Solids loading: 20 vol. \%; Prepared by Method IV.

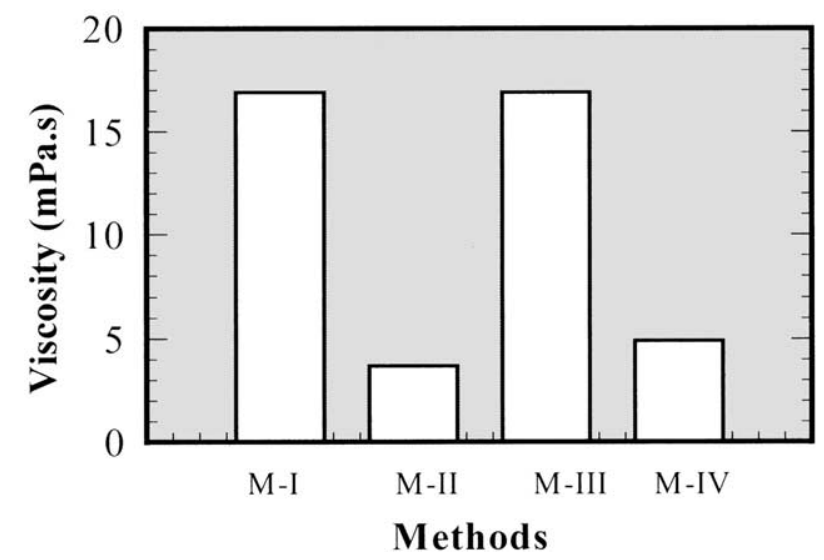

Fig. 5. Effect of F-127, concentration on the viscosity of aqueous alumina suspensions. Shear rate: 200 1/s, Solid loading: $20 \mathrm{vol} \%$.

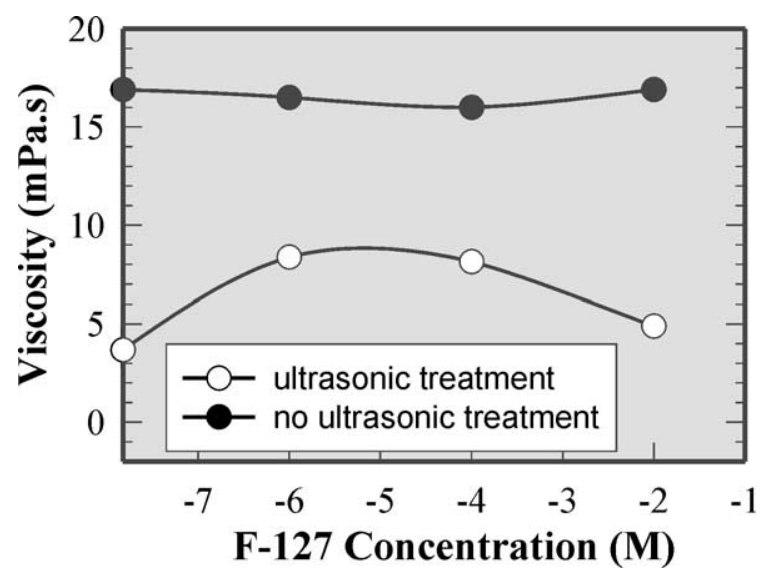

Fig. 6. Effect of suspension preparation method on the viscosity of alumina/water systems. Shear rate: 200 1/s; Solids loading: 20 vol.\%; Prepared by Method III and IV.

were lower than the viscosities of the suspensions prepared by the other methods.

\subsection{Sedimentation measurements}

The settling behaviour of alumina particles was studied by measuring the sediment height as a function of time to observe the stability of this system for longer times. In these tests once the dispersion was achieved the stirring was stopped and the particles were allowed to settle under hindered settling conditions. The results are presented as sediment height versus time plots in Fig. 7. The effect of F-127 concentration on this system is also given in Fig. 8 up to $420 \mathrm{~h}$. It is seen from the figures that application of Method I and Method III is not enough to provide a stable system and therefore sediment height is higher in these cases. However, using ultrasonic treatment (Method II and IV) decreases the sediment height. This is in accord with the findings of rheological studies. Effect of dispersant concentration, on the other hand, becomes more important if there is no ultrasonic treatment applied to the system (Fig. 8).

\subsection{Turbidity measurements in dilute suspensions}

Turbidity measurements were carried out to study the settling behaviour of very dilute $(0.125 \mathrm{vol} . \%)$ alumina suspensions where particles settle with their terminal velocities. Again, once the suspensions were prepared by one of the methods the stirring was stopped and the particles were allowed to settle. The turbidity of these suspensions was measured as a function of time and the results were presented in Fig. 9. Since presence of flocculates in the system will lower the turbidity, the lower values in case of Method I and III indicates the presence of aggregates in the system, compared with the systems obtained by Method II and IV. However, these suspensions were quite stable during the time period of 


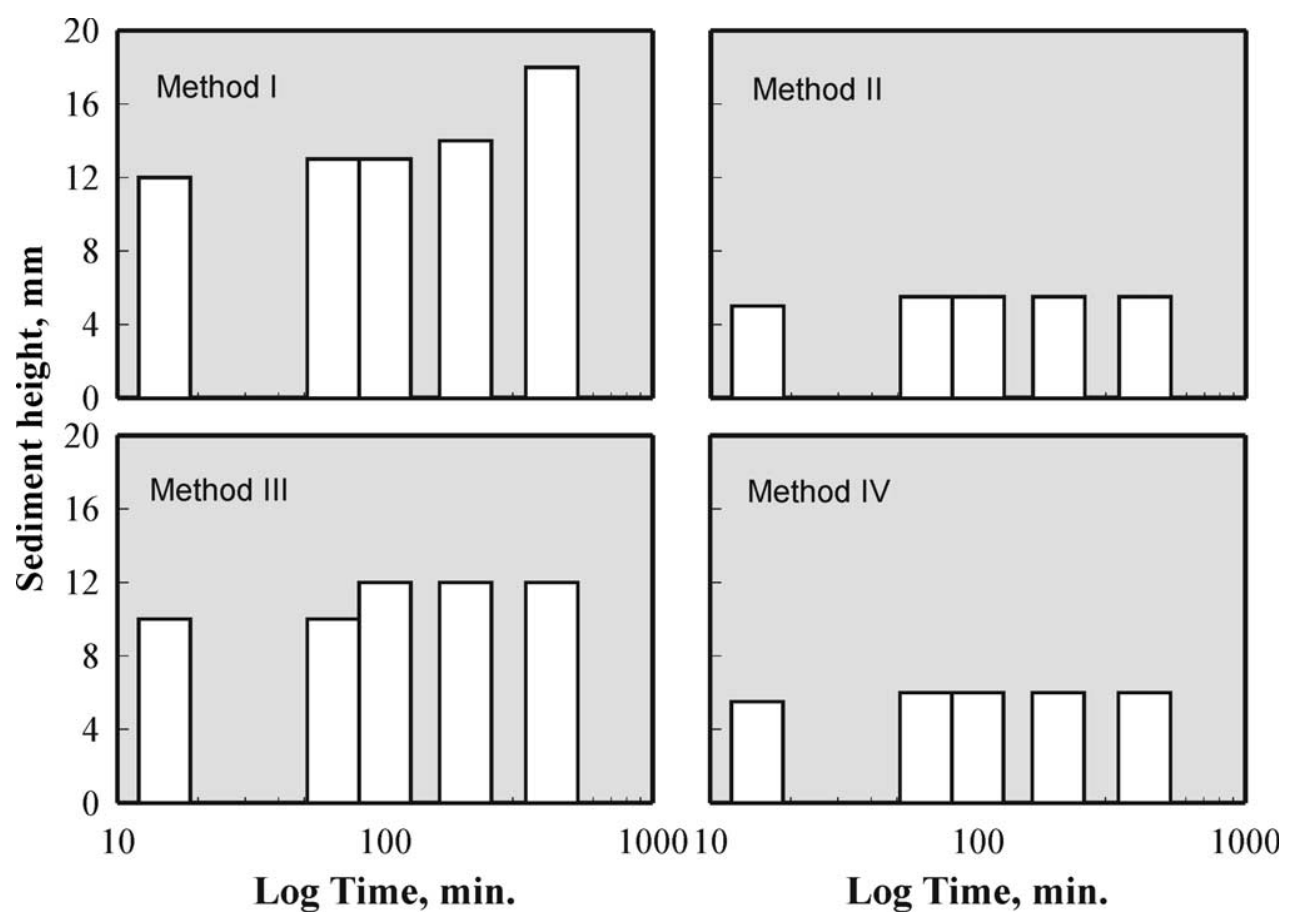

Fig. 7. Effect of suspension preparation method on the settling behaviour of alumina particles in water. Solids loading: 20 vol. $\%$.
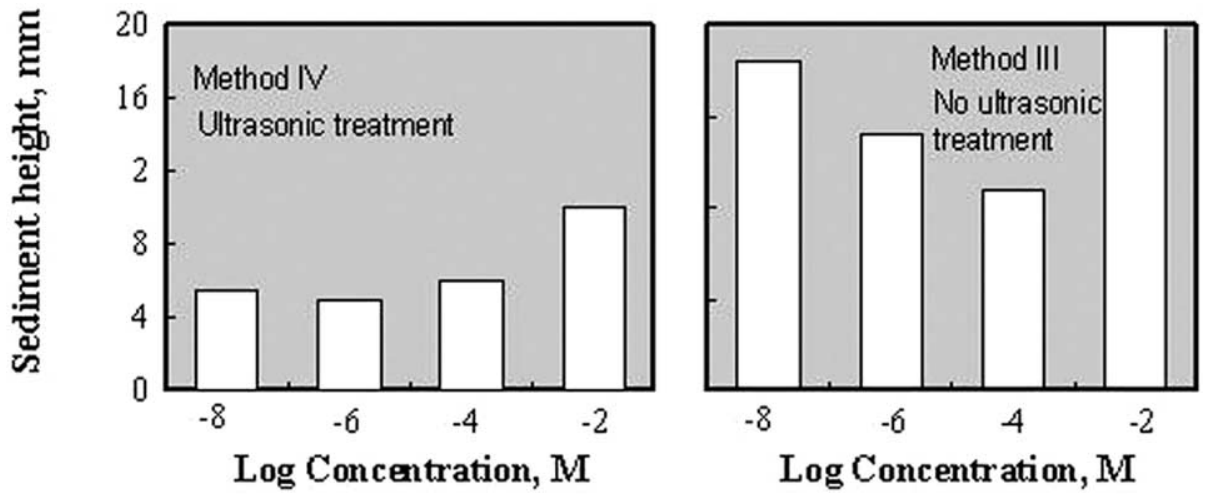

Fig. 8. Effect of F-127 concentration on the settling behaviour of alumina particles in water. Solids loading: 20 vol.\%; Prepared by Method III and IV.

experiments (64 min). Method II and IV gave higher turbidity values due to well dispersion of particles. Among the two, Method IV, where block copolymer and ultrasonic treatment were used together, seems to provide better dispersion than Method II, where ultrasonic treatment was used alone. Sedimentation and rheological measurements, where high solids loadings were used, did not show any difference between these two methods.

\subsection{Total interaction potential curves of the system}

When two particles in a suspension approach each other, the double layers become to overlap, which leads to a repulsive interaction between the two particles due to the increased concentration of ions in the overlapping double layers. When the suspension is stable, each particle is kept separated from the other by the repulsive potential. The DLVO theory has been widely used to model the total interaction potential energy (Vt) of aqueous colloidal suspensions. The repulsive potential energy arising from electrostatic charges on particles and attractive potential energy due to van der Waals interaction forces for two spherical particles with radii $a$ can be given by: ${ }^{20}$

$$
\begin{aligned}
\operatorname{Vr}(h)= & \frac{\pi \cdot \varepsilon \cdot \varepsilon_{o} \cdot a_{1} \cdot a_{2}}{k \cdot T \cdot\left(a_{1}+a_{2}\right)} \cdot\left[2 \cdot \psi_{1} \cdot \psi_{2} \cdot \ln \left(\frac{1+e^{-\kappa \cdot h}}{1-e^{-\kappa \cdot h}}\right)\right. \\
& \left.+\left(\psi_{1}^{2}+\psi_{2}^{2}\right) \cdot \ln \left(1-\mathrm{e}^{-2 \cdot \kappa \cdot h}\right)\right]
\end{aligned}
$$




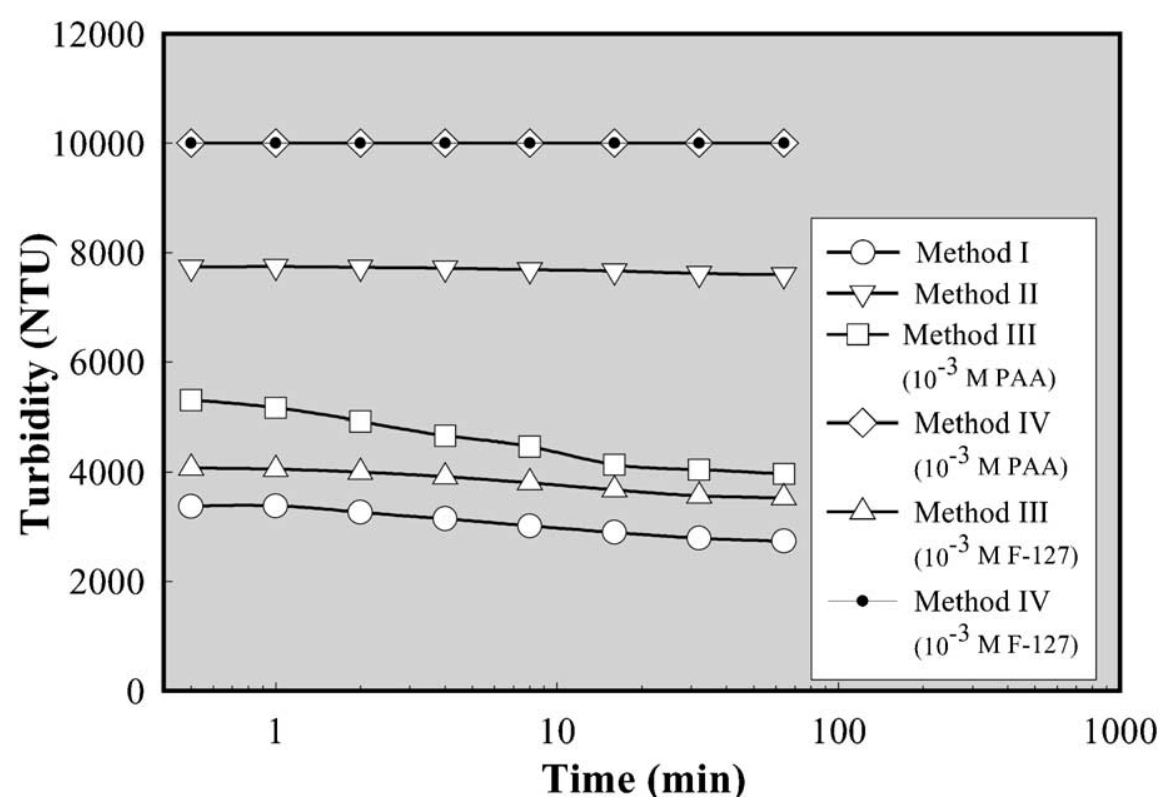

Fig. 9. Effect of suspension preparation method on the turbidity of alumina particles in water. Solids loading: 0.125 vol. $\%$; $10^{-3}$ M F-127 and $10^{-3}$ M PAA.

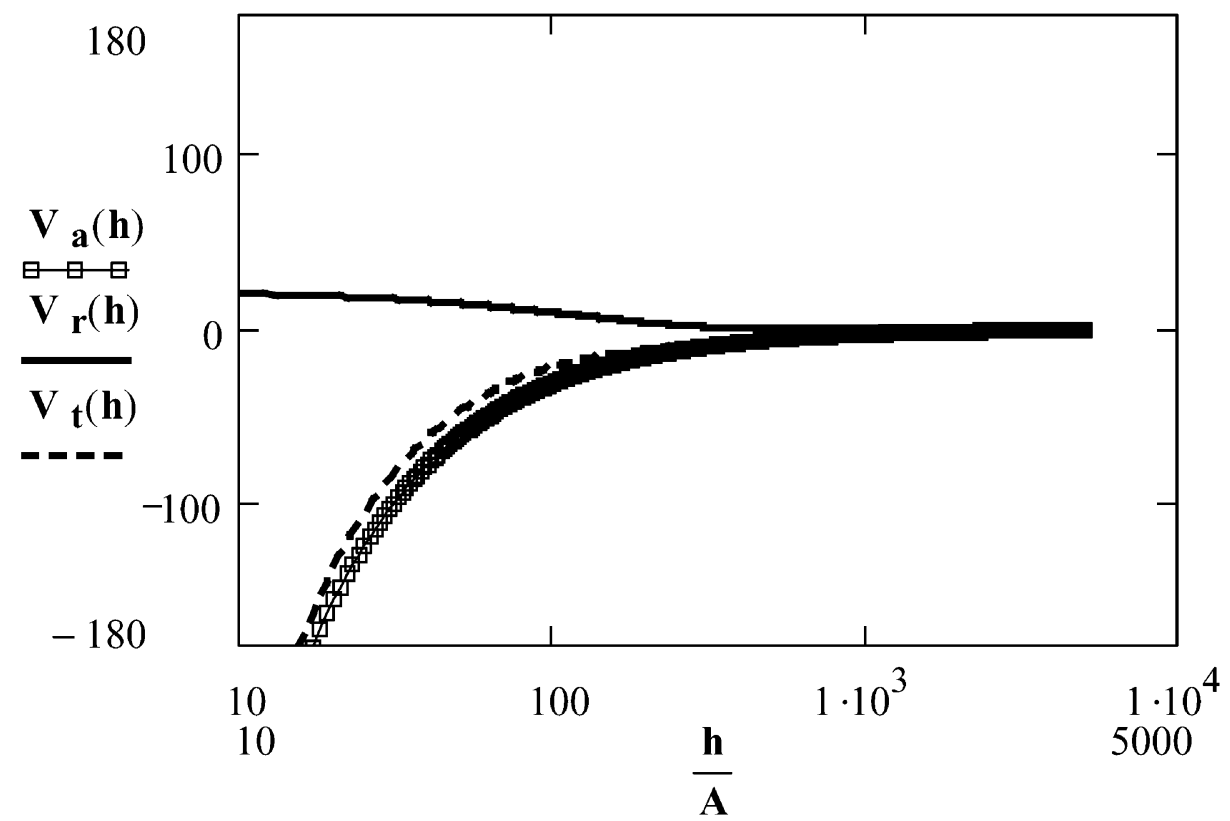

Fig. 10. Total interaction potential graph of aqueous alumina suspension prepared by Method I. Solids loading 0.125 vol. $\%$. $T=298 \mathrm{~K} ; z=1$; Hamaker constant of $\mathrm{Al}_{2} 0_{3}, A_{121}=5.08 \times 10^{-20} \mathrm{~J}, a_{1}=a_{2}=0.3 \mu \mathrm{m} ; \psi_{1}=\psi_{2}=\xi=0.010 \mathrm{volt} ; \kappa=1.0438 \times 10^{8} \mathrm{~m}^{0.8} \mathrm{~mol}^{-0.5}$.

$\mathrm{Va}(h)=-\frac{A_{121} \cdot a_{1} \cdot a_{2}}{6 \cdot k \cdot T \cdot\left(a_{1}+a_{1}\right) \cdot h}$

$\operatorname{Vt}(h)=\operatorname{Vr}(h)+\operatorname{Va}(h)$

where

$\kappa=\sqrt{\frac{2 \cdot z^{2} \cdot F^{2} \cdot C_{o}}{R \cdot T \cdot \varepsilon \cdot \varepsilon_{o}}}$
In this study, it was assumed that the system consists of identical particles. The zeta potentials $(\xi)$ of particles under different conditions were measured and these values were used as surface potentials since they are nearly equal. Without an ionic additive the stability of aqueous alumina suspensions is controlled by electrostatic forces due to ionized sites at the oxide surface. Therefore, only electrostatic interactions were taken into consideration. The expressions given above for electrostatic interactions were used to calculate the total 


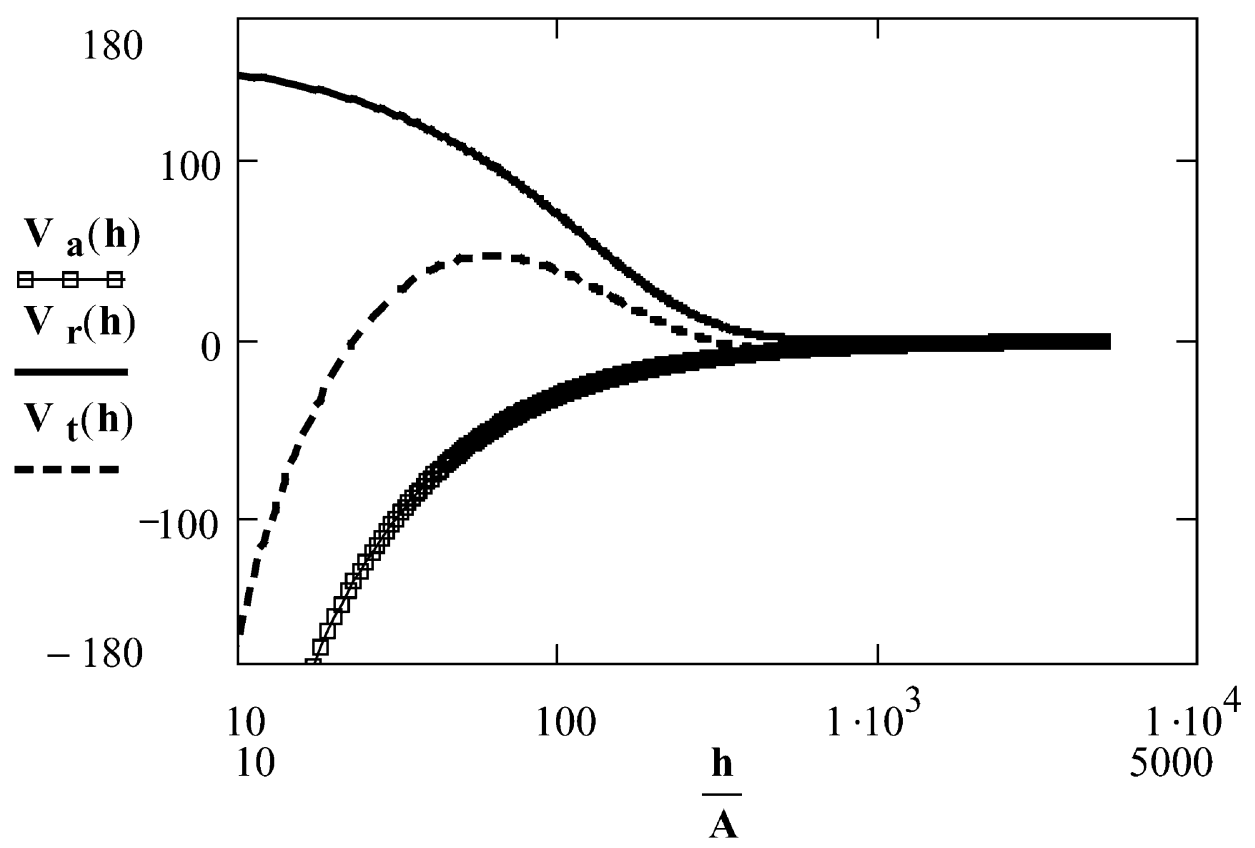

Fig. 11. Total interaction potential graph of aqueous alumina suspension prepared by Method IV. Solids loading 0.125 vol. $\%$. $T=298 \mathrm{~K} ; z=1$; Hamaker constant of $\mathrm{Al}_{2} \mathrm{O}_{3}, A_{121}=5.08 \times 10^{-20} \mathrm{~J}, a_{1}=a_{2}=0.3 \mu \mathrm{m} ; \psi_{1}=\psi_{2}=\xi=0.027$ volt; $\kappa=1.0438 \times 10^{8} \mathrm{~m}^{0.8} \mathrm{~mol}^{-0.5}$.

interaction energy for a sample case of two interacting spherical alumina particles. Results are shown in Fig. 10 for the system prepared by Method I and in Fig. 11 for the system prepared by Method IV, respectively. The first system achieved a flocculated state as it is indicated in the diagram. However, the second system has a higher energy barrier and repulsive interaction potential. Alumina particles in water are strongly attached to each other as indicated by their large Hamaker constant. However, when Vr is sufficiently large, a greater potential barrier keeps the particles from forming an attractive network. In this case the particles are repelled from each other and flow as individual units. The viscosity is essentially Newtonian under these conditions.

\subsection{Adsorption studies}

Surface tension measurements were conducted to study adsorption of block copolymers onto alumina surface. For the powder/water/surfactant mixtures the surface tension measured is indicative of the excess surface concentration of the air/water interface, which is also related to the concentration of surfactant in aqueous solution. The difference between the original surfactant concentration before equilibrium with the powder and the concentration indicated by the surface tension measurement can be converted into a powder/ surfactant concentration. ${ }^{21}$ The differences in surface tension values of the suspensions that include alumina and without alumina (including only the surfactant) were attributed to the concentration difference caused by the adsorption of polymer molecules on the alumina surface. The addition of alumina to the system produces an increase in surface tension if there is surfactant adsorption onto the solid surface.

The validity of the surface tension technique depends on the chemical equilibrium between the air/water interface and solid/water interface, which imply the surfactant molecules, are exchanged reversibly at both interfaces with surfactant molecules in bulk water. If this condition can be performed then the plot of the concentration of surfactant present in aqueous phase against surface tension can be used as a calibration graph. $^{21}$

Fig. 12 presents surface tension /surfactant concentration data obtained for F-127 in the absence and presence of alumina powder. There is a break in the curve at a concentration between $10^{-5}$ and $10^{-6} \mathrm{~mol}^{-1}$ for F-127. This result agrees with the other reported surface tension data. ${ }^{13,16,17}$ Results showed that at polymer concentration close to the critical micelle concentration, adsorption of surfactant to the powder reaches a plateau. Similar observations have been reported by Paterson et al. for adsorption of this kind of polymers onto soil and by Levitz et al 1991 for hydrophilic solid/water interfaces. ${ }^{21}$

It is also known that, for polymers adsorbed onto solid surface, the adsorption isotherm show three regions. At small polymer concentration the adsorbed amount is proportional with the equilibrium polymer concentration. If the polymer concentration continues to increase and exceeds a certain value a pseudo-plateau region develops which indicates the saturation. At very high polymer concentrations the adsorption start to decrease. $^{22}$ 


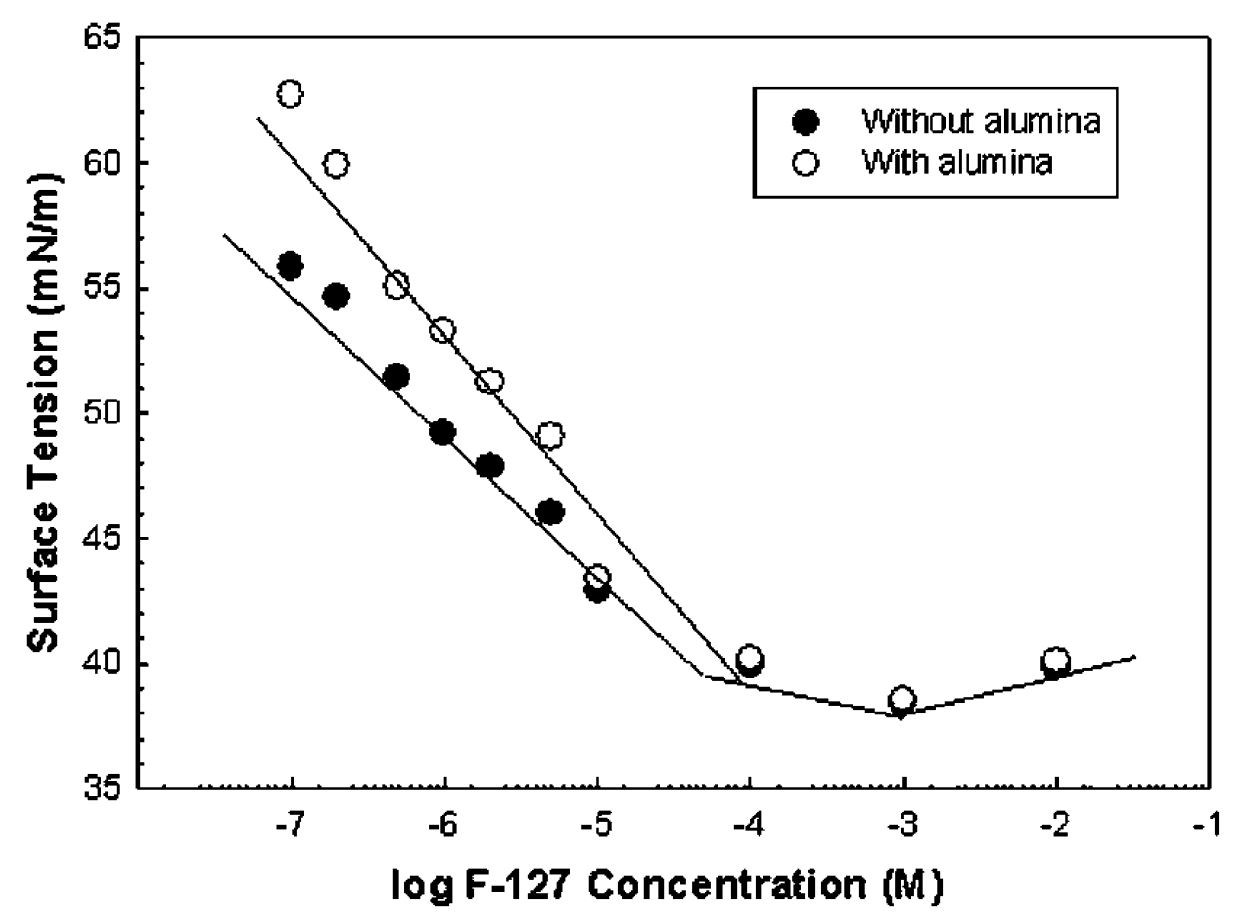

Fig. 12. Surface tension versus F-127 concentration in the absence and presence of alumina. Solids loading: 5 vol. $\%$.

\subsubsection{Discussion on adsorption of PEO-PPO-PEO}

block copolymers based on literature

Adsorption studies help to elucidate the mechanisms of adsorption of block copolymers onto pure hydrophobic and hydrophilic substrates. For hydrophilic surfaces, adsorption occurs through ethylene oxide groups (PEO) by hydrogen bonding between the oxygen of the EO groups and the surface. For hydrophobic surfaces, the adsorption of block copolymers occurs via the hydrophobic portion (PPO) of the molecules through hydrophobic attraction. ${ }^{12}$

Although Alexsandridis et al. ${ }^{13}$ have indicated the adsorption of non-ionic surfactants on hydrophilic surfaces, Hergeth et al. ${ }^{18}$ reported PEO adsorbs on silica but not on alumina. It was proposed that for PEO to adsorb on oxide surface, the polymer has to displace enough water molecules bonded to the solid surface and create strong entropy effects. In case of strongly hydrated alumina surface the polymer is unable to displace sufficient water molecules necessary for adsorption. However, there is no explanation for the differences in the adsorption behaviour of the alumina and silica.

Guo et al. ${ }^{23}$ reported that the presence of the free polymer in the system might cause weak flocculation due to depletion effect. Also effect of free polymer on flocculation becomes stronger as the volume fraction of alumina increases. But the mechanism was unclear and further investigation is suggested.

The effect of a nonadsorbing polymer on the interaction between the colloidal particles, termed the depletion effect, has been observed extensively in many polymer/particle combinations. The general observation is that increasing concentrations of the polymer causes the particle dispersion to flocculate. In some cases the dispersions are further re-stabilized at higher polymer concentrations.

It is also known that in liquid-powder systems such as suspensions, the water film drainage between the particles is necessary for agglomeration and the presence of dispersant molecules or micelles in water affect the drainage of this film and prevents agglomeration. ${ }^{24}$ This means, these molecules might create dispersion in the system even though there is no adsorption on the surface.

\section{Conclusions}

The dispersion and stability of aqueous alumina suspensions in the absence and presence of polyethylene oxide-polypropylene oxide-polyethylene oxide (PEOPPO-PEO) type block copolymers was investigated in this study. According to the results following conclusions were made:

\subsection{Rheological studies}

- The use of ultrasonic treatment (Method II) was sufficient to overcome the flocculation and obtain a dispersed system for all solids loadings. Method IV showed similar results with Method II.

- Without ultrasonic treatment using block copolymer, F-127 (Method III), was not efficient 
enough to obtain a Newtonian behaviour for the alumina suspensions. The reason for the flocculation of the system in Method III might be attributed to the bridging effect or depletion flocculation mechanism, which occurs at small particle separations.

\subsection{Sedimentation and turbidity studies}

- Sedimentation tests showed that settling behaviour of these suspensions are in accord with the rheological findings. At high solids loadings (as in the case of rheological measurements and sedimentation), without ultrasonic treatment, the effect of a block copolymer was not significant. In case of low solids loadings (as in the case of turbidity measurements), on the other hand, the effect of using a block copolymer was significant.

- According to the outputs of the turbidity measurements, for Method IV (ultrasonic treatment and use of F-127), turbidity values were higher (better dispersion) compared to Method II (only ultrasonic treatment).

- Polyacrylic acid was used for comparison purposes in the same system. At $10^{-3} \mathrm{M}$ concentration PAA also behaved very similar to F-127.

\subsection{Adsorption studies}

- The adsorption of non-ionic surfactant, F-127 onto alumina has been examined by surface tension measurements. It was observed that the addition of alumina to the water/polymer solution caused increases in surface tension indicating the presence of surgactant adsorption on the alumina suface.

\section{References}

1. Cahn, R. W., Haasen, P. and Kramer, E. J., Structure and properties of ceramics. Material Science and Technology, 1994, 11, 84 87.

2. Heimenz, P. C., Principles of Colloid and Surface Chemistry, 3rd edn. Marcel Dekker, 1997.

3. Binner, J. G. P. and Davies, J., The role of ammonium polyacrylate in dispersing concentrated alumina suspensions. J. Eur. Ceram. Soc., 2000, 20, 1539-1553.

4. Reed, J. S., Principles of Ceramic Processing, 2nd edn. John Wiley and Sons, Canada, 1995.

5. Evanko, C., Dzombak, D. and Novak, J., Influence of surfactant addition on the stability of concentrated alumina dispersions in water. Colloid and Surfaces A: Physicochemical and Engineering Aspects, 1996, 110, 219-223.
6. Hidber, P., Graule, T. and Gauckler, L., Influence of the dispersant structure on properties of electrostatically stabilized aqueous alumina suspensions. J. Eur. Ceram. Soc., 1997, 17, 239-249.

7. Hidber, P., Graule, T. and Gauckler, L., Citric acid - a dispersant for aqueous alumina suspensions. J. Am. Ceram. Soc., 1996, 79, 1857-1867.

8. Bertrand, C., Filiatre, C., Mahdjoub, H., Foissy, A. and Coddet, C., Influence of slurry characteristics on the morphology of spraydried alumina powders. J. Eur. Ceram. Soc., 2003, 23, 263-271.

9. Dakskobler, A., Kocevar, K. and Kosmac, T., Short range repulsive potential developed by the addition of $\mathrm{Mg}$ (II) ions to aqueous alumina slurries. J. Eur. Ceram. Soc., 2001, 21, 23612368.

10. Greenwood, R., Kendall, K., Ritchie, S. and Snowden, M. J., The use of poly ( $\mathrm{N}$ - isopropylacrylamide) microgels as a multifunctional processing aid for aqueous alumina suspensions. $J$. Eur. Ceram. Soc., 2000, 20, 1707-1716.

11. Baklouti, S., Romdhane, M., Boufi, S., Pagnoux, C., Chrtier, T. and Baumard, J., Effect of copolymer dispersant structure on the properties of alumina suspensions. J. Eur. Ceram. Soc., 2002, 23.

12. Desai, P. R., Jain, H. J., Sharma, R. K. and Bahadur, P., Effect of additives on the micellization of $\mathrm{PEO} / \mathrm{PPO} / \mathrm{PEO}$ block copolymers F 127 in aqueous solution. Colloids and Surfaces, A: Physicochemical and Engineering Aspects, 2001, 178, 57-69.

13. Alexandridis, P., Athanassiou, V. and Fukuda, S., Surface activity of poly (-ethylene oxide)-block-poly(propylene oxide) block poly(ethylene oxide ) copolymers. J. Am. Chem. Soc., 1994, 10, 2604-2612.

14. Faers, M. and Luckham, P. F., Rheology of polyethylene oxidepolypropylene oxide blockcopolymer stabilized latices and emulsions. Colloid and Surfaces A: Physicochemical and Engineering Aspects, 1994, 86, 327-347.

15. Miano, F., Bailey, A., Luckham, P. F. and Tadros, F., Adsorption of poly (ethylene oxide)- poly (propylene oxide) ABA block copolymers on carbon black and the rheology of the resulting dispersions. Colloids and Surfaces, 1992, 68, 9-16.

16. Wanka, G., Hoffmann, H. and Ulbricht, L., The aggregation behaviour of poly-(oxyetylene)-poly-(oxypropylene)-poly-(oxyetylene)-block copolymers in aqueous solution. Colloid and Polymer Science, 1990, 268, 101-117.

17. Polat, H., Polat, M. and Chander S., Adsorption behaviour of $\mathrm{PEO} / \mathrm{PPO}$ triblock copolymers on coals of different ranks. In Proceedings of the XX IMPC-Aachen, 21-26 September. 1997, pp. 725-734.

18. Hergeth, W. D., Zimmermann, R. and Schmutzler, K., Adsorption of POE-POP-POE block copolymers onto silica. Colloids and Surfaces, 1991, 56, 177-187.

19. Cesarano, I. I. I. J. and Aksay, I., Processing of highly concentrated aqueous $\alpha$-alumina suspensions stabilized with polyelectrolytes. J. Am. Ceram. Soc., 1988, 71, 1062-1067.

20. Guo, J. J. and Lewis, A. J., Effects of ammonium chloride on rheological properties and sedimentation behaviour of aqueous silica suspensions. J. Am. Ceram. Soc., 2000, 83, 266-272.

21. Paterson, F., Chowdhry, B. and Carey, P., Leharne S, Examination of the adsorption of ethylene oxide-propylene oxide triblock copolymers to soil. J. Contaminant Hydrology, 1999, 40, $37-51$.

22. Gosa, K. L. and Uricanu, V., Emulsions stabilized with PEOPPO-PEO block copolymers and silica. Colloids and Surfaces A: Physicochemical and Engineering Aspects, 2002, 197, 257-269.

23. Guo, L., Zhang, Y., Uchida, N. and Uematsu, K., Adsorption effects on the rheological properties of aqueous alumina suspensions with polyelectrolyte. J. Am. Ceram. Soc., 1998, 81, 549-556.

24. Polat, H. and Chander S., Adsorption of PEO/PPO Tri Block Copolymers at Air/water and Coal/Water Interfaces. $\mathrm{PhD}$ thesis, Pen State University, USA, 1985. 